\title{
ORIGINAL
}

\section{Physiological and quantitative CT-scan characterization of COVID-19 and typical ARDS: a matched cohort study}

\author{
Davide Chiumello ${ }^{1}$, Mattia Busana², Silvia Coppola ${ }^{1}$, Federica Romitti ${ }^{2}$, Paolo Formenti ${ }^{1}$, Matteo Bonifazi ${ }^{2}$, \\ Tommaso Pozzi ${ }^{1}$, Maria Michela Palumbo ${ }^{2}$, Massimo Cressoni ${ }^{3}$, Peter Herrmann², Konrad Meissner ${ }^{2}$, \\ Michael Quintel ${ }^{2}$, Luigi Camporota ${ }^{4}$, John J. Marini ${ }^{5}$ and Luciano Gattinoni ${ }^{2^{*}}$ (1)
}

() 2020 The Author(s)

\begin{abstract}
Purpose: To investigate whether COVID-19-ARDS differs from all-cause ARDS.

Methods: Thirty-two consecutive, mechanically ventilated COVID-19-ARDS patients were compared to two historical ARDS sub-populations 1:1 matched for $\mathrm{PaO}_{2} / \mathrm{FiO}_{2}$ or for compliance of the respiratory system. Gas exchange, hemodynamics and respiratory mechanics were recorded at 5 and $15 \mathrm{cmH}_{2} \mathrm{O}$ PEEP. CT scan variables were measured at 5 $\mathrm{CmH}_{2} \mathrm{O}$ PEEP.

Results: Anthropometric characteristics were similar in COVID-19-ARDS, $\mathrm{PaO}_{2} / \mathrm{FiO}_{2}$-matched-ARDS and Compliance-matched-ARDS. The $\mathrm{PaO}_{2} / \mathrm{FiO}_{2}$-matched-ARDS and COVID-19-ARDS populations (both with $\mathrm{PaO}_{2} / \mathrm{FiO}_{2}$ $106 \pm 59 \mathrm{mmHg}$ ) had different respiratory system compliances (Crs) (39 $\left.\pm 11 \mathrm{vs} 49.9 \pm 15.4 \mathrm{ml} / \mathrm{cmH}_{2} \mathrm{O}, p=0.03\right)$. The Compliance-matched-ARDS and COVID-19-ARDS had similar Crs (50.1 \pm 15.7 and $49.9 \pm 15.4 \mathrm{ml} / \mathrm{cmH}_{2} \mathrm{O}$, respectively) but significantly lower $\mathrm{PaO}_{2} / \mathrm{FiO}_{2}$ for the same $\mathrm{Crs}(160 \pm 62$ vs $106.5 \pm 59.6 \mathrm{mmHg}, p<0.001)$. The three populations had similar lung weights but COVID-19-ARDS had significantly higher lung gas volume $\left(\mathrm{PaO}_{2} / \mathrm{FiO}_{2}\right.$-matched-ARDS $930 \pm 644 \mathrm{ml}$, COVID-19-ARDS $1670 \pm 791 \mathrm{ml}$ and Compliance-matched-ARDS $1301 \pm 627 \mathrm{ml}, p<0.05)$. The venous admixture was significantly related to the non-aerated tissue in $\mathrm{PaO}_{2} / \mathrm{FiO}_{2}$-matched-ARDS and Compliance-matchedARDS $(p<0.001)$ but unrelated in COVID-19-ARDS $(p=0.75)$, suggesting that hypoxemia was not only due to the extent of non-aerated tissue. Increasing PEEP from 5 to $15 \mathrm{cmH}_{2} \mathrm{O}$ improved oxygenation in all groups. However, while lung mechanics and dead space improved in $\mathrm{PaO}_{2} / \mathrm{FiO}_{2}$-matched-ARDS, suggesting recruitment as primary mechanism, they remained unmodified or worsened in COVID-19-ARDS and Compliance-matched-ARDS, suggesting lower recruitment potential and/or blood flow redistribution.
\end{abstract}

Conclusions: COVID-19-ARDS is a subset of ARDS characterized overall by higher compliance and lung gas volume for a given $\mathrm{PaO}_{2} / \mathrm{FiO}_{2}$, at least when considered within the timeframe of our study.

Keywords: COVID-19, ARDS, Respiratory system mechanics, Mechanical ventilation, CT scan

*Correspondence: gattinoniluciano@gmail.com

${ }^{2}$ Department of Anesthesiology, Intensive Care and Emergency

Medicine, Medical University of Göttingen, Robert-Koch Straße 40, Göttingen, Germany

Full author information is available at the end of the article

\section{Introduction}

Acute respiratory distress syndrome (ARDS) - as currently defined-is a syndrome which broadly includes diverse conditions grouped on the basis of an oxygenation deficit of acute onset and bilateral radiographic infiltrates that cannot be attributed solely to a 
cardiovascular cause [1]. The severity of ARDS is classified by a single criterion only: oxygenation deficit, expressed as $\mathrm{PaO}_{2} / \mathrm{FiO}_{2}$ ratio. By this broad definition, hypoxemic patients with coronavirus disease 2019 (COVID-19) and bilateral chest X-ray infiltrates clearly satisfy the definition of ARDS. We have reported [2, 3] that severe hypoxemia with relatively well-preserved respiratory system compliance (Crs) measured under standard conditions is characteristic of COVID-19ARDS, and it differs from ARDS of other causes (typical ARDS), while others did not recognize consistent differences [4-7]. However, the increased frequency of higher Crs in COVID-19-ARDS was noted by some of the same authors $[4,5]$, and a significantly higher Crs associated with severe hypoxemia was recently documented [8]. The heterogeneous nature of ARDS allows that-at the population level-there may be wide overlap between COVID-19-ARDS and typical ARDS, and these observations continue to drive a debate $[6,9]$. It is worth remembering that during the Berlin conference, the experts' panel initially agreed on using an upper threshold of $40 \mathrm{ml} / \mathrm{cmH}_{2} \mathrm{O}$ of respiratory system compliance $(\mathrm{Crs})$ to qualify as severe ARDS. This variable was not implemented, however, as it did not add further prognostic value to bilateral infiltrates and $\mathrm{PaO}_{2} /$ $\mathrm{FiO}_{2}$ ratio [10]. In other words, the $\mathrm{PaO}_{2} / \mathrm{FiO}_{2}$ ratio and the $\mathrm{Crs}$ deteriorated together in typical ARDS. This pairing may not occur in COVID-19-ARDS, where a discrepancy between the severities of hypoxemia and respiratory mechanics may be the key issue, rather than their individual absolute values per se.

Indeed, this discrepancy could be due to the underlying pathogenesis of COVID-19-ARDS, which is highly atypical and quite distinct from most other forms of typical ARDS that are routinely encountered $[2,11$, 12]. In typical ARDS, the primary site 'hit' is the alveolar space, particularly in pulmonary ARDS. In contrast, in COVID-19-ARDS, the prevalent pathophysiological mechanism is initiated on the vascular side of the pulmonary unit. In addition, the endothelialitis, typical of COVID-19 patients, results in a powerful activation of the coagulation cascade, with micro and macro thrombosis occurring in pulmonary tissues and throughout the body [13-15]. Undoubtedly, microthromboses are recognized autopsy findings [16], and pulmonary artery filling defects (vascular occlusion or compression) have been described in typical ARDS for decades [17, 18]. A striking difference between typical ARDS and COVID-19ARDS, however, is the remarkable frequency and extent to which pulmonary $[15,19]$ and extrapulmonary thrombosis [20] occur in the latter. While regional atelectasis, edema and fibrosis may coexist, disrupted vasoregulation strikingly alters the matching of perfusion to ventilation, a pathophysiologic mechanism which may be the predominant contributor to hypoxemia in the early phase of this evolving disease [12, 21].

To investigate whether and to what degree, COVID19-ARDS differs from typical ARDS, we compared the physio-anatomical characteristics of COVID-19-ARDS patients with two historically matched cohorts of typical ARDS. Quantitative CT scan analysis, and measurements of respiratory system mechanics and gas exchange were performed under standardized and identical conditions, both in COVID-19-ARDS and typical ARDS, thus avoiding the biases of acquiring $\mathrm{CT}$ scans and physiological variables under highly heterogeneous "clinical" conditions.

\section{Methods}

\section{Study population}

Thirty-two COVID-19-ARDS patients, consecutively admitted to the ICU of ASST Santi Paolo e Carlo Hospital, Milan over the period between February 21st, 2020 and May 7th, 2020 were prospectively enrolled. This study was conducted in accordance with the pre-existing Ethics Committee approval that allows physiological and CT scan studies for all patients with severe respiratory failure admitted to our critical care unit (ethics committee numbers: 42937/2016 and 9890/2017). All had documented COVID-19 positive RT-PCR o nasal or pharyngeal swab and bilateral infiltrates documented by chest X-ray. This COVID-19-ARDS population was matched with cohorts from two separate non-COVID ARDS populations: one matched 1:1 for $\mathrm{PaO}_{2} / \mathrm{FiO}_{2}\left(\mathrm{PaO}_{2} / \mathrm{FiO}_{2}\right.$-matched-ARDS $)$ and a second one matched 1:1 for respiratory system compliance (Compliance-matched-ARDS). The values of $\mathrm{PaO}_{2} / \mathrm{FiO}_{2}$ ratio and $\mathrm{Crs}$ used for matching these cohorts were the ones measured in COVID-19-ARDS at $5 \mathrm{cmH}_{2} \mathrm{O}$ of PEEP during mechanical ventilation, immediately before the CT scan. The $\mathrm{PaO}_{2} / \mathrm{FiO}_{2}$ ratio and Crs of the two historical non-COVID ARDS cohorts were measured under exactly the same conditions.

The two matched, entirely independent population samples were extracted from our ARDS dataset which includes 232 patients studied between 2003 and 2018. These patients had previously been screened and included in clinical physiopathologic studies performed by our group over the same time span. Therefore, they met all criteria that define ARDS and underwent a common and standardized intervention (e.g., CT scan, PEEP trials, measurement of respiratory mechanics and gas exchange) and a standardized data collection protocol.

\section{Measurements}

In every studied patient (of both COVID-19-ARDS and the matched non-COVID ARDS populations), gas exchange, respiratory mechanics, hemodynamics and 
CT scan variables were recorded under standardized conditions (Volume Controlled ventilation, tidal volume $7-8 \mathrm{ml} / \mathrm{kg}$ of Ideal Body Weight (IBW), muscle relaxation, $5 \mathrm{cmH}_{2} \mathrm{O}$ of Positive End-Expiratory Pressure, PEEP). Both COVID-19-ARDS and non-COVID ARDS population cohorts underwent CT scanning and PEEP testing within a median of 3 [IQR $1-4]$ days after the admission to ICU.

\section{Gas exchange}

We measured $\mathrm{FiO}_{2}, \mathrm{PO}_{2}, \mathrm{PCO}_{2}$, hemoglobin saturation and derived variables (using arterial and central venous blood) and end-tidal $\mathrm{PCO}_{2}\left(\mathrm{P}_{\mathrm{ET}} \mathrm{CO}_{2}\right)$. Venous admixture was computed using central venous blood values as surrogates for the mixed venous ones [22].

\section{Respiratory system mechanics}

We measured plateau pressure, PEEP, driving pressure and respiratory system compliance at the standardized value of $5 \mathrm{cmH}_{2} \mathrm{O}$.

\section{CT-quantitative anatomical variables}

In each patient, the whole lung CT was performed under static conditions during an end-expiratory hold at $5 \mathrm{cmH}_{2} \mathrm{O}$ of PEEP. Lung profiles of each CT scan slice were manually contoured, excluding hilar structures. Then, quantitative analysis was performed with dedicated software (Maluna [23]). We estimated lung weight, gas volume, amount of over-inflated tissue (voxel density -1000 to -900 Hounsfield Units, HU), well-aerated tissue $(-899$ to $-500 \mathrm{HU})$, poorly aerated tissue $(-499$ to $-100 \mathrm{HU})$ and non-aerated tissue $(-100$ to $+100 \mathrm{HU})$. Analyses were performed on each whole slice as well as on ten equally spaced segments along the sterno-vertebral axis.

\section{PEEP response}

All patients underwent a "PEEP-test" in which PEEP was raised from 5 to $15 \mathrm{cmH}_{2} \mathrm{O}$ while keeping constant respiratory rate, tidal volume and $\mathrm{FiO}_{2}$. Gas exchange, hemodynamics and mechanical variables were re-measured at $15 \mathrm{cmH}_{2} \mathrm{O}$ of PEEP after a 15-min equilibration period (See Supplement for details.)

\section{Statistical analysis}

The one-to-one matching procedure was performed with the nearest-neighboring method using the optimal algorithm, without replacement, with the MatchIt package for $\mathrm{R}$ ( $\mathrm{R}$ Foundation for Statistical Computing version 4.0.2) [24]. Data are presented as mean \pm standard deviation. Student's $t$ test assessed the statistical significance of the difference between group means when data were distributed normally; otherwise, the Wilcoxon test was used. Chi square test or Fisher's exact test was used to construct the contingency tables. Linear regression tested the relationship between continuous variables. Two-way analysis of variance allowing interaction was used to evaluate the gas volume distribution along the segments of sterno-vertebral axis. These statistical analyses were performed with R (R Foundation for Statistical Computing version 4.0.2) and its package Tidyverse.

\section{Results}

\section{Study population}

COVID-19-ARDS (32 consecutive patients) and both non-COVID ARDS population cohorts $\left(\mathrm{PaO}_{2} / \mathrm{FiO}_{2}-\right.$ matched-ARDS and Compliance-matched-ARDS, 32 patients each) had similar baseline characteristics regarding age, sex, Ideal Body Weight and Body Mass Index. The Simplified Acute Physiology Score II (SAPSII), although lower in COVID-19-ARDS patients, was not statistically different from the comparison cohorts. However, it is likely that overall clinical severity in the $\mathrm{PaO}_{2} /$ $\mathrm{FiO}_{2}$-matched-ARDS and Compliance-matched-ARDS groups was greater, as indicated by longer ICU length of stay (Table 1). $\mathrm{PaO}_{2} / \mathrm{FiO}_{2}$-matched-ARDS and Compliance-matched-ARDS had comparable distributions of prevalence regarding etiology of lung injury $(p=0.86)$. The majority (68.7\%) of both COVID-19-ARDS and $\mathrm{PaO}_{2} / \mathrm{FiO}_{2}$-matched-ARDS patients had $\mathrm{PaO}_{2} / \mathrm{FiO}_{2}$ ratios consistent with severe ARDS, based on the Berlin definition of ARDS severity. In contrast, severe ARDS represented only $18.7 \%$ of Compliance-matched-ARDS patients; $(p<0.001)$ (Table 1$)$. Outcome measures for the three populations are reported in Table 1.

\section{Oxygenation and respiratory mechanics}

When COVID-19-ARDS was compared to the $\mathrm{PaO}_{2} /$ $\mathrm{FiO}_{2}$-matched-ARDS cohort, i.e., at similar oxygenation, its respiratory system compliance was significantly higher $\left(49.9 \pm 15.4\right.$ vs $39.9 \pm 11.1 \mathrm{ml} / \mathrm{cmH}_{2} \mathrm{O} ; p=0.003$, Fig. 1a) and plateau and driving pressures were significantly lower (Table 2). When COVID-19-ARDS was compared to the Compliance-matched-ARDS population, i.e., at similar respiratory system mechanics, the $\mathrm{PaO}_{2} /$ $\mathrm{FiO}_{2}$ ratio was significantly lower in COVID-19-ARDS $(106.5 \pm 59$ vs $160 \pm 62 \mathrm{mmHg} ; p<0.001$, Fig. $1 \mathrm{~b})$, as were the other oxygenation variables. In $\mathrm{PaO}_{2} / \mathrm{FiO}_{2}$-matchedARDS patients, the $\mathrm{PaO}_{2} / \mathrm{FiO}_{2}$ ratio was linearly related with the respiratory system mechanics $(p=0.036)$, whereas no significant correlation was found neither in Compliance-matched-ARDS $(p=0.9)$, nor in COVID-19$\operatorname{ARDS}(p=0.81$, Figure E1). 
Table 1 Baseline clinical characteristics of the three cohorts

\begin{tabular}{|c|c|c|c|c|c|}
\hline & PF-ARDS $(n=32)$ & $p$ value & CARDS $(n=32)$ & $p$ value & Crs-ARDS $(n=32)$ \\
\hline Age (years) & $59 \pm 17$ & 0.96 & $58.9 \pm 8.9$ & 0.15 & $63.8 \pm 16.2$ \\
\hline Female $(n-\%)$ & $8(25)$ & 0.2 & $4(12)$ & 0.21 & $9(28.1)$ \\
\hline Height (cm) & $171 \pm 10$ & 0.14 & $175 \pm 9$ & 0.054 & $170 \pm 9$ \\
\hline Ideal Body Weight (kg) & $66.5 \pm 9.9$ & 0.85 & $66.9 \pm 7.2$ & 0.47 & $65.3 \pm 9.8$ \\
\hline $\mathrm{BMI}\left(\mathrm{kg} / \mathrm{m}^{2}\right)$ & $29 \pm 8.2$ & 0.57 & $28 \pm 4.1$ & 0.11 & $26 \pm 6$ \\
\hline $\mathrm{PaO}_{2} / \mathrm{FiO}_{2}(\mathrm{mmHg})$ & $106.3 \pm 59.4$ & 0.99 & $106.5 \pm 59.6$ & $<0.001$ & $160 \pm 62$ \\
\hline $\mathrm{Crs}\left(\mathrm{ml} / \mathrm{cmH}_{2} \mathrm{O}\right)$ & $39 \pm 11.1$ & 0.003 & $49.9 \pm 15.4$ & 0.97 & $50.1 \pm 15.7$ \\
\hline \multicolumn{6}{|l|}{ Causes of lung injury $(n-\%)$} \\
\hline Pneumonia & $17(53.1)$ & & $32(100)$ & & $14(43.8)$ \\
\hline Aspiration & $3(9.4)$ & & $0(0)$ & & $2(6.3)$ \\
\hline Sepsis & $6(18.7)$ & & $0(0)$ & & $8(25)$ \\
\hline Trauma & $3(9.4)$ & & $0(0)$ & & $3(9.4)$ \\
\hline Other & $3(9.4)$ & & $0(0)$ & & $5(15.6)$ \\
\hline \multicolumn{6}{|l|}{ ARDS category $(n-\%)$} \\
\hline Mild & $3(9.4)$ & 1 & $3(9.4)$ & $<0.001$ & $7(21.9)$ \\
\hline Moderate & $7(21.9)$ & & $7(21.9)$ & & $19(59.4)$ \\
\hline Severe & $22(68.7)$ & & $22(68.7)$ & & $6(18.8)$ \\
\hline SAPSII & $43.5 \pm 21.3$ & 0.07 & $34.5 \pm 12.1$ & 0.07 & $41.1 \pm 15.5$ \\
\hline $\begin{array}{l}\text { Days of mechanical ventilation } \\
\text { before study }\end{array}$ & $2.2 \pm 2.2$ & $<0.001$ & $0.8 \pm 0.7$ & 0.002 & $3.8 \pm 4.5$ \\
\hline ICU length of stay (days) & $19.2 \pm 12.2$ & 0.07 & $13.7 \pm 8.1$ & $<0.001$ & $24.8 \pm 13.4$ \\
\hline ICU mortality $(n-\%)$ & $17(53.1)$ & 0.21 & $12(37.5)$ & 1 & $12(37.5)$ \\
\hline
\end{tabular}

Anthropometric and clinical characteristics of COVID-19-ARDS population (CARDS, middle column) and the two historical matched cohorts (PaO ${ }_{2} / \mathrm{FiO}_{2}$-matchedARDS, left column and Compliance-matched-ARDS, right column)

BMI Body Mass Index, Crs respiratory system compliance, SAPSII Simplified Acute Physiology Score II, ICU Intensive Care Unit

\section{$\mathrm{CO}_{2}$ clearance and dead space}

With regard to the ventilation parameters, COVID-19ARDS and its two matched populations $\left(\mathrm{PaO}_{2} / \mathrm{FiO}_{2}-\right.$ matched-ARDS and Compliance-matched-ARDS) had comparable values for tidal volume, alveolar dead space ventilation and ventilatory ratio. Minute ventilation was significantly higher and $\mathrm{PaCO}_{2}$ lower in COVID-19ARDS, compared to $\mathrm{PaO}_{2} / \mathrm{FiO}_{2}$-matched-ARDS, due to a higher respiratory rate (Table 2 ).

\section{CT scan variables}

Despite similar total lung weights, patients with COVID-19-ARDS, compared to $\mathrm{PaO}_{2} / \mathrm{FiO}_{2}$-matchedARDS, had significantly higher lung gas volume $(1670 \pm 791$ vs $930 \pm 644 \mathrm{~mL} ; p<0.001)$, a greater amount of normally aerated tissue $(475 \pm 185$ vs $287 \pm 154 \mathrm{~g} ; \quad p<0.001)$ and less non-aerated tissue $(591 \pm 293$ vs $960 \pm 567$ g; $p=0.002)$ (Table 2). The weights of the normally aerated and non-aerated lung tissues were similar in COVID-19-ARDS and in Compliance-matched-ARDS populations, but total lung gas volume was higher in COVID-19-ARDS compared to Compliance-matched-ARDS. Notably, the distribution of gas volume was remarkably different for the three populations: patients with COVID-19-ARDS had the highest gas volumes in each lung segment, whereas the lowest gas volumes were measured in the corresponding segments of the $\mathrm{PaO}_{2} / \mathrm{FiO}_{2}$-matched ARDS population (Fig. 2).

Hemodynamics, venous admixture and non-aerated tissue Hemodynamic values are presented in Table 2. In Fig. 3, we present venous admixture as a function of the fraction of non-aerated tissue. In each of the nonCOVID ARDS cohorts, venous admixture increased with the fraction of non-aerated tissue (both $p=0.004$ ). In contrast, in COVID-19-ARDS, the venous admixture remained approximately constant and independent from large variations in the observed fraction of non-aerated tissue $(p=0.75)$. The regression model also shows that in the COVID-19-ARDS population the constant term of the model equates to a venous admixture of 0.50 (95\% CI 0.33-0.67), suggesting that significant venous admixture is theoretically present, even for an assumed zero fraction of non-aerated tissue. $\mathrm{PaO}_{2} /$ $\mathrm{FiO}_{2}$ ratio and $\mathrm{A}-\mathrm{aPO}_{2}$ as a function of the fraction 

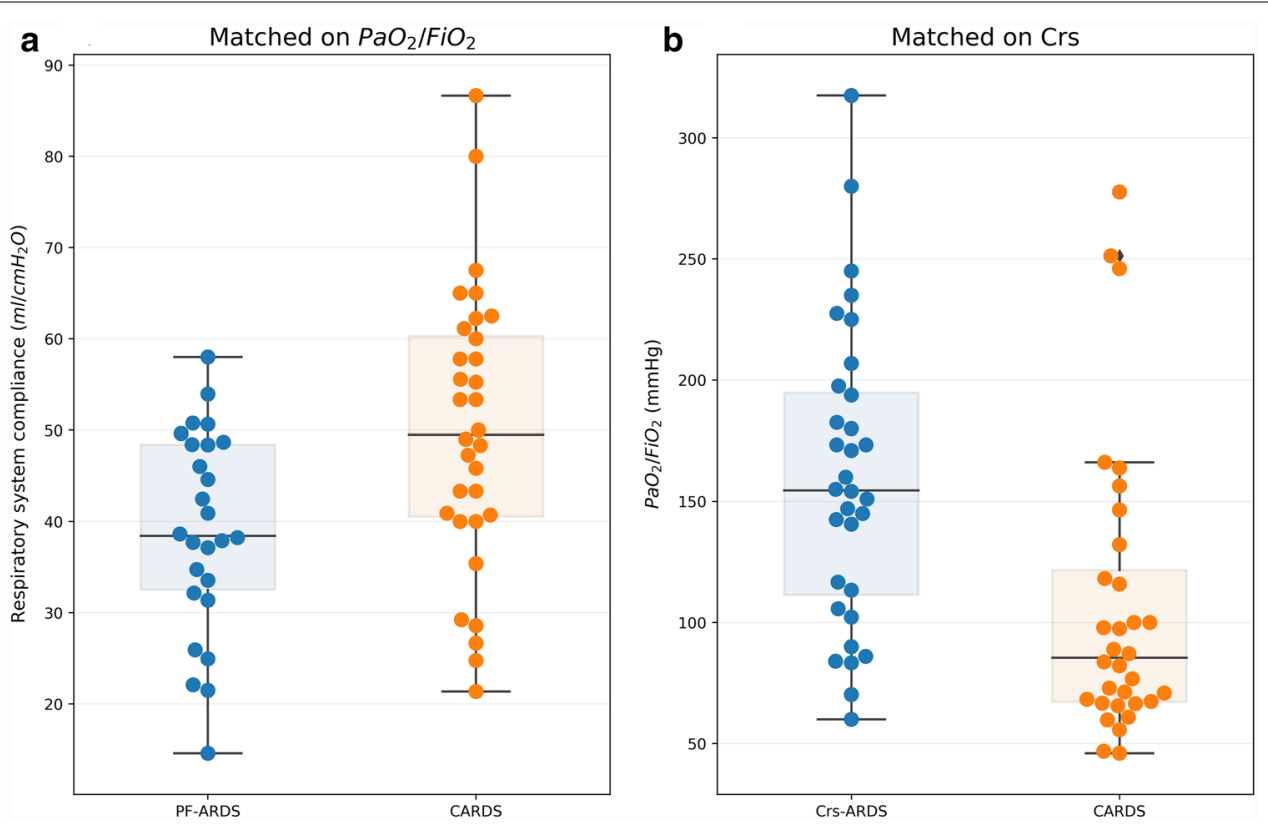

Fig. 1 a Respiratory system compliance in COVID-19-ARDS (orange) and in $\mathrm{PaO}_{2} / \mathrm{FiO}_{2}$-matched-ARDS populations (blue). The matched $\mathrm{PaO} /$ $\mathrm{FiO}_{2}$ ratios were similar (COVID-19-ARDS $=106 \pm 59 \mathrm{mmHg}, \mathrm{PaO}_{2} / \mathrm{FiO}_{2}$-matched-ARDS $=106 \pm 60 \mathrm{mmHg}$ ). Note that, for the $\mathrm{same} \mathrm{PaO}_{2} / \mathrm{FiO}_{2}$ ratio, the $\mathrm{Crs}$ in COVID-19-ARDS is significantly higher $\left(\sim 11 \mathrm{ml} / \mathrm{cmH}_{2} \mathrm{O}\right.$ ) than in $\mathrm{PaO}_{2} / \mathrm{FiO}_{2}$-matched-ARDS (median values $49.5 \mathrm{and} 38.4 \mathrm{ml} / \mathrm{cmH}_{2} \mathrm{O}$, respectively). $\mathbf{b} \mathrm{PaO}_{2} / \mathrm{FiO}_{2}$ ratio in COVID-19-ARDS (orange) and in Compliance-matched-ARDS populations (blue). The matched respiratory system compliance values were similar (COVID-19-ARDS $=49.9 \pm 15.4 \mathrm{ml} / \mathrm{cmH}_{2} \mathrm{O}$, Compliance-matched-ARDS $\left.=50.1 \pm 15.7 \mathrm{ml} / \mathrm{cmH}_{2} \mathrm{O}\right)$. Note that, for the same $\mathrm{Crs}$, the $\mathrm{PaO}_{2} / \mathrm{FiO}_{2}$ ratio in Compliance-matched-ARDS is significantly higher ( $70 \mathrm{mmHg}$ ) than in COVID-19-ARDS (median values 155.0 and $85.4 \mathrm{mmHg}$, respectively)

of non-aerated tissue (Figures E2 and E3) showed the same behavior of venous admixture.

\section{Response to PEEP test}

The responses of the physiological variables to the PEEP test, i.e., increasing PEEP from 5 to $15 \mathrm{cmH}_{2} \mathrm{O}$ are summarized in Table 3. As shown, despite a similar increase in oxygenation in all three populations, the respiratory system mechanics and dead space all improved in the $\mathrm{PaO}_{2} / \mathrm{FiO}_{2}$-matched-ARDS cohort but did not change or deteriorated in patients with COVID-19-ARDS and those with Compliance-matched-ARDS.

\section{Discussion}

In this study, which compares COVID-19-ARDS patients with two different non-COVID-19 ARDS populations, we found the following: (1) COVID-19-ARDS patients, compared to $\mathrm{PaO}_{2} / \mathrm{FiO}_{2}$-matched ARDS (i.e., similar oxygenation), had consistently better respiratory system compliance and nearly double the end-expiratory gas volume as their counterparts in the comparison groups; (2) COVID-19-ARDS patients, compared to a separate population of non-COVID-19 ARDS patients matched on Crs (i.e., with similar respiratory system mechanics) had consistently worse oxygenation variables; (3)
COVID-19-ARDS, $\quad \mathrm{PaO}_{2} / \mathrm{FiO}_{2}$-matched-ARDS, and Compliance-matched-ARDS experienced similar oxygenation improvement when raising PEEP from 5 to 15 $\mathrm{cmH}_{2} \mathrm{O}$. Importantly, however, while that oxygenation improvement in the $\mathrm{PaO}_{2} / \mathrm{FiO}_{2}$-matched-ARDS population was associated with significantly improved $\mathrm{CO}_{2}$ clearance and respiratory mechanics, these variables did not change or deteriorated in both COVID-19-ARDS patients and Compliance-matched-ARDS patients.

\section{Patient populations}

A single matching variable was used for each matching procedure. No other variables were included, due to the limited size of our ARDS dataset. The anthropometric characteristics of the three populations were not statistically different. Bilateral pneumonia was the only cause of lung injury in COVID-19-ARDS patients. By comparison, pneumonia accounted for $53.1 \%$ and $43.8 \%$ in $\mathrm{PaO}_{2} /$ $\mathrm{FiO}_{2}$-matched-ARDS and Compliance-matched-ARDS cohorts, respectively, incidence frequencies similar to the LUNG-SAFE study (59.4\%) of 3022 patients $(p=0.16)$ [25]. The prevalence of sepsis was also similar among LUNG-SAFE, $\mathrm{PaO}_{2} / \mathrm{FiO}_{2}$-matched-ARDS and Compliance-matched-ARDS $(16 \%, 18.7 \%$ and $25 \%$ in, respectively; $p=0.36$ ). Therefore, our sample of matched ARDS 
Table 2 Gas exchange, respiratory mechanics, hemodynamics and CT variables of the three cohorts

\begin{tabular}{|c|c|c|c|c|c|}
\hline & PF-ARDS $(n=32)$ & $p$ value & CARDS $(n=32)$ & $p$ value & Crs-ARDS $(n=32)$ \\
\hline \multicolumn{6}{|l|}{ Oxygenation } \\
\hline $\mathrm{FiO}_{2}$ & $0.74 \pm 0.22$ & 0.66 & $0.72 \pm 0.18$ & $<0.001$ & $0.51 \pm 0.15$ \\
\hline $\mathrm{PaO}_{2}(\mathrm{mmHg})$ & $68.1 \pm 17.4$ & 0.75 & $66.7 \pm 16.8$ & 0.045 & $76.1 \pm 19.6$ \\
\hline $\mathrm{PaO}_{2} / \mathrm{FiO}_{2}(\mathrm{mmHg})$ & $106.3 \pm 59.4$ & 0.99 & $106.5 \pm 59.6$ & $<0.001$ & $160 \pm 62$ \\
\hline $\mathrm{PAO}_{2}(\mathrm{mmHg})$ & $465 \pm 148$ & 0.73 & $453 \pm 129$ & $<0.001$ & $313 \pm 107$ \\
\hline $\mathrm{AaPO}_{2}(\mathrm{mmHg})$ & $397 \pm 156$ & 0.77 & $386 \pm 138$ & $<0.001$ & $237 \pm 113$ \\
\hline $\mathrm{SaO}_{2}(\%)$ & $90.2 \pm 5.3$ & 0.78 & $90.6 \pm 5.7$ & 0.056 & $93.1 \pm 4.1$ \\
\hline \multicolumn{6}{|l|}{$\mathrm{CO}_{2}$ clearance } \\
\hline Tidal volume (ml/kg IBW) & $7.5 \pm 1.6$ & 0.52 & $7.7 \pm 0.9$ & 0.07 & $8.4 \pm 1.9$ \\
\hline Respiratory rate (bpm) & $16.8 \pm 3.9$ & 0.014 & $18.7 \pm 2$ & $<0.001$ & $15.7 \pm 3.6$ \\
\hline Minute ventilation (I/min) & $8.18 \pm 2.21$ & 0.002 & $9.82 \pm 1.85$ & 0.001 & $8.3 \pm 1.76$ \\
\hline $\mathrm{PaCO}_{2}(\mathrm{mmHg})$ & $50.9 \pm 13.6$ & 0.027 & $44.7 \pm 7.1$ & 0.60 & $45.8 \pm 9.9$ \\
\hline $\mathrm{P}_{\mathrm{ET}} \mathrm{CO}_{2}(\mathrm{mmHg})$ & $35.1 \pm 8.6$ & 0.44 & $33.6 \pm 5.2$ & 0.034 & $37.2 \pm 7.5$ \\
\hline Alveolar dead space & $0.29 \pm 0.18$ & 0.17 & $0.23 \pm 0.12$ & 0.17 & $0.19 \pm 0.14$ \\
\hline Ventilatory ratio & $1.72 \pm 0.69$ & 0.77 & $1.76 \pm 0.45$ & 0.11 & $1.57 \pm 0.47$ \\
\hline \multicolumn{6}{|l|}{ Respiratory Mechanics } \\
\hline Plateau pressure $\left(\mathrm{cmH}_{2} \mathrm{O}\right)$ & $19.5 \pm 4.1$ & 0.035 & $17.2 \pm 3.8$ & 0.49 & $16.6 \pm 3.7$ \\
\hline Driving pressure $\left(\mathrm{cmH}_{2} \mathrm{O}\right)$ & $13.9 \pm 4.2$ & 0.014 & $11.3 \pm 3.7$ & 0.64 & $11.7 \pm 3.7$ \\
\hline Compliance $_{\mathrm{rs}}\left(\mathrm{ml} / \mathrm{cmH}_{2} \mathrm{O}\right)$ & $39 \pm 11.1$ & 0.003 & $49.9 \pm 15.4$ & 0.97 & $50.1 \pm 15.7$ \\
\hline \multicolumn{6}{|l|}{ Hemodynamics } \\
\hline Heart rate (bpm) & $92.1 \pm 20.6$ & 0.008 & $79 \pm 18$ & 0.018 & $89.3 \pm 16.5$ \\
\hline Mean arterial pressure $(\mathrm{mmHg})$ & $80.2 \pm 9.4$ & 0.09 & $85 \pm 12$ & 0.06 & $79.7 \pm 10.4$ \\
\hline $\mathrm{ScvO}_{2}(\%)$ & $75.4 \pm 9.25$ & 0.52 & $73.9 \pm 6.5$ & 0.30 & $76.5 \pm 9.5$ \\
\hline$(\mathrm{a}-\mathrm{v}) \mathrm{O}_{2}$ difference $(\mathrm{ml} / \mathrm{dl})$ & $1.9 \pm 1.14$ & 0.004 & $2.78 \pm 0.78$ & 0.19 & $2.37 \pm 1.24$ \\
\hline Venous admixture & $0.6 \pm 0.24$ & 0.049 & $0.48 \pm 0.15$ & 0.51 & $0.44 \pm 0.26$ \\
\hline Haemoglobin (mg/dl) & $10.4 \pm 1.5$ & $<0.001$ & $12 \pm 1.5$ & $<0.001$ & $10.1 \pm 1.1$ \\
\hline \multicolumn{6}{|l|}{ CT scan } \\
\hline Lung weight (g) & $1729 \pm 705$ & 0.35 & $1596 \pm 385$ & 0.12 & $1409 \pm 538$ \\
\hline Lung gas volume (ml) & $930 \pm 644$ & $<0.001$ & $1670 \pm 791$ & 0.043 & $1301 \pm 627$ \\
\hline Hyperinflated tissue (g) & $2.85 \pm 7.68$ & 0.08 & $7.68 \pm 13$ & 0.47 & $4.80 \pm 18$ \\
\hline Normally aerated tissue (g) & $287 \pm 154$ & $<0.001$ & $475 \pm 185$ & 0.14 & $412 \pm 150$ \\
\hline Poorly aerated tissue (g) & $479 \pm 250$ & 0.48 & $522 \pm 196$ & 0.07 & $426 \pm 418$ \\
\hline Non-aerated tissue (g) & $960 \pm 567$ & 0.002 & $591 \pm 293$ & 0.8 & $566 \pm 475$ \\
\hline
\end{tabular}

Gas exchange, respiratory mechanics, hemodynamics and CT scan variables measured in COVID-19-ARDS (CARDS, middle column) and the two historical matched cohorts $\left(\mathrm{PaO}_{2} / \mathrm{FiO}_{2}\right.$-matched-ARDS, left column and Compliance-matched-ARDS, right column)

$\mathrm{PaO}_{2}$ arterial partial pressure of oxygen, $P A \mathrm{O}_{2}$ alveolar partial pressure of oxygen, $A-a P \mathrm{O}_{2}$ alveolar-arterial oxygen partial pressure difference, $\mathrm{SaO}$, hemoglobin saturation of the arterial blood, $\mathrm{PaCO}_{2}$ arterial partial pressure of carbon dioxide, $\mathrm{PETCO}_{2}$ end-tidal partial pressure of carbon dioxide, ScvO $\mathrm{O}_{2}$ hemoglobin saturation of the central venous blood, $(a-v) \mathrm{O}_{2}$ difference arterial-venous difference of oxygen content

patients appears representative of the ARDS populations enrolled in pre-COVID ARDS clinical trials. The distribution of mild, moderate and severe ARDS (as measured at $5 \mathrm{cmH}_{2} \mathrm{O}$ of PEEP [26]) in COVID-19-ARDS and in our $\mathrm{PaO}_{2} / \mathrm{FiO}_{2}$-matched-ARDS subgroup was identical (Table 2) [1]. In contrast, the overall severity of Compliance-matched-ARDS patients was lower, as the prevalence of severe ARDS category was only $18.8 \%$ vs $68.7 \%$ in COVID-19-ARDS. The general clinical severity, as indicated by SAPSII, tended to be lower in COVID-19-ARDS patients, compared to the two non-Covid ARDS populations, perhaps accounting for their shorter length of stay in the ICU.

\section{Oxygenation, lung mechanics and the mechanism of hypoxemia}

Differently from typical ARDS, where the decrease of $\mathrm{PaO}_{2} / \mathrm{FiO}_{2}$ ratio is associated with a decrease in Crs, in our COVID-19-ARDS population $\mathrm{PaO}_{2} / \mathrm{FiO}_{2}$ ratio and $\mathrm{Crs}$ were unrelated. This has also been found in a recent 


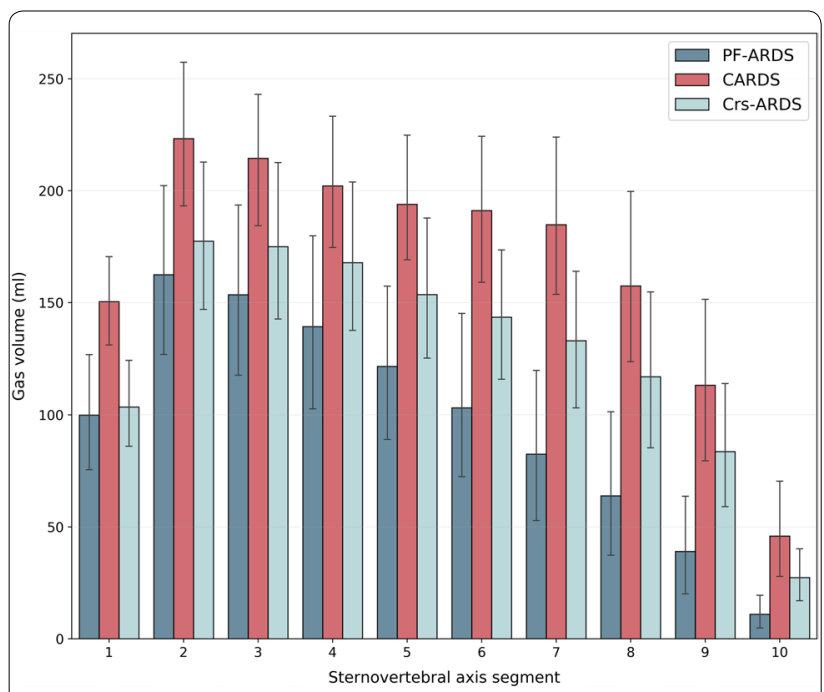

Fig. 2 Lung gas volume measured in the 10 equally spaced lung segments along the sterno-vertebral axis (level $1=$ closest to the sternum, level $10=$ closest to the vertebra). The gas volume of both the $\mathrm{PaO}_{2} / \mathrm{FiO}_{2}$-matched-ARDS (dark blue) and Compliance-matchedARDS (light blue) was significantly different from COVID-19-ARDS ( $p<0.001$ and $p=0.043$, respectively). Note that the gas volume was higher in COVID-19-ARDS, even compared to the Compliancematched-ARDS. The extent of the differences is particularly evident in the most dependent lung regions, where the gas volume at each level was even more than double in COVID-19-ARDS than in $\mathrm{PaO}_{2}$ / $\mathrm{FiO}_{2}$-matched-ARDS larger study comparing typical ARDS with COVID19-ARDS [8]. This contrasts with the decision taken in Berlin to exclude Crs from the ARDS definition as unnecessary, as it added no prognostic value to the $\mathrm{PaO}_{2} / \mathrm{FiO}_{2}$ ratio alone [10]. It is then possible that the mechanisms leading to hypoxemia are somehow different between COVID-19-ARDS and typical ARDS. Hypoxemia due to venous admixture [27] originates from two potential mechanisms: true right to left shunt (i.e., perfusion of non-aerated tissue) and/or low ventilation-perfusion $\left(V_{\mathrm{A}} / Q\right)$ ratio (perfusion of poorly ventilated lung regions). In typical ARDS, the primary component of venous admixture is right-to-left shunt. Accordingly, the greater the fraction of non-aerated tissue, the greater the venous admixture [28, 29]. In COVID-19-ARDS the venous admixture was unrelated to the non-aerated tissue fraction; indeed, it was very high even when the fraction of non-aerated tissue was very low (Fig. 3). This observation strongly suggests that the major component of the venous admixture in COVID-19-ARDS is ventilationperfusion mismatch, rather than true right-to-left shunt. The important role of $V_{\mathrm{A}} / Q$ mismatch in COVID-19ARDS is consistent with (but not entirely explained by) the reported high incidence of micro and macro thrombosis in this disease $[11,14,30,31]$ and with the importance of markers of immune-thrombosis (e.g., D-dimers) in the outcome of COVID-19-ARDS [8].

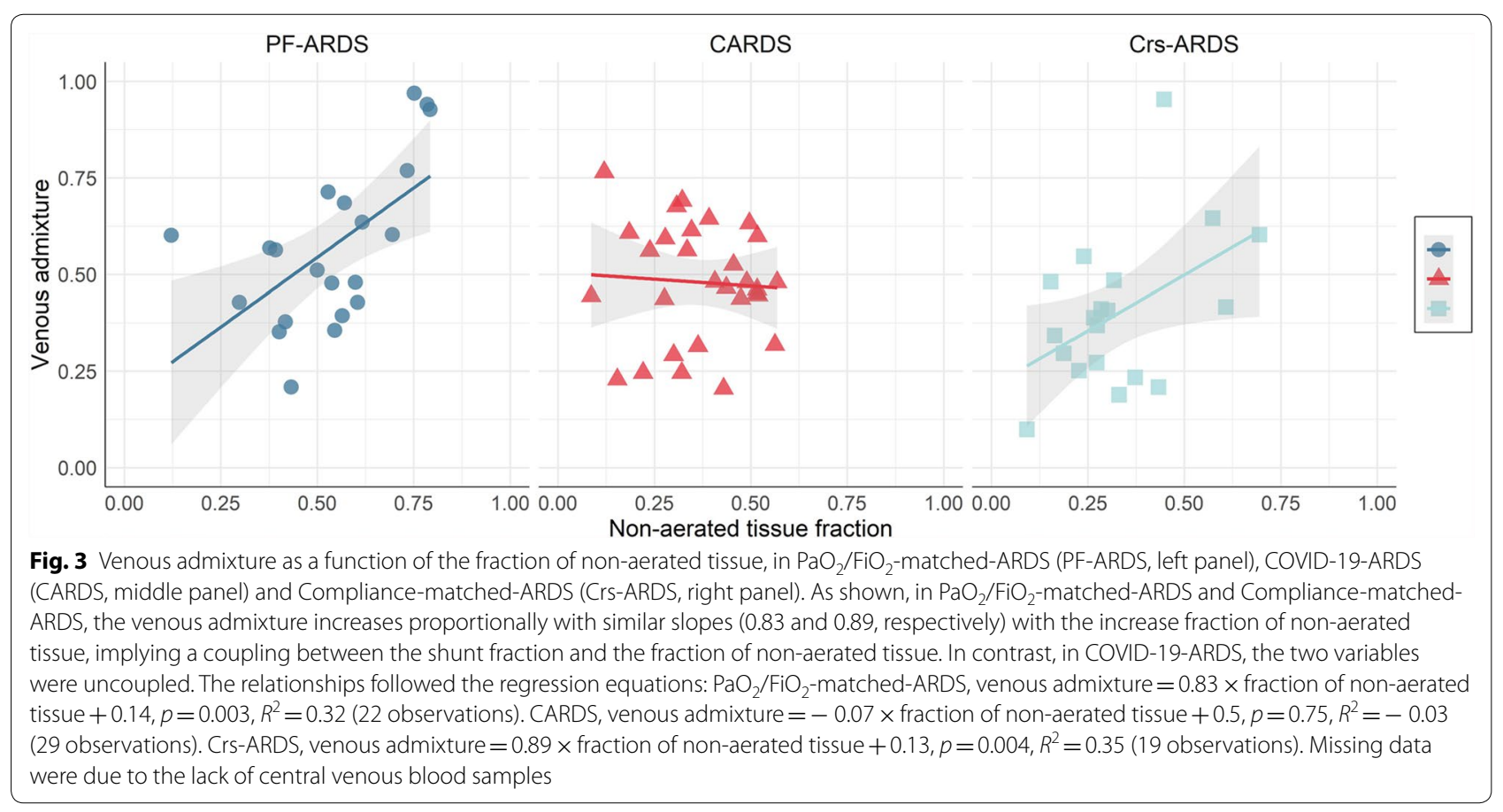


Table 3 Gas exchange, respiratory mechanics and hemodynamic response to the PEEP increase $\left(5-15 \mathrm{cmH}_{2} \mathrm{O}\right)$

\begin{tabular}{|c|c|c|c|c|c|}
\hline & PF-ARDS $(n=32)$ & $p$ value & CARDS $(n=32)$ & $p$ value & Crs-ARDS $(n=32)$ \\
\hline \multicolumn{6}{|l|}{ Oxygenation } \\
\hline$\triangle \mathrm{PaO}_{2}(\mathrm{mmHg})$ & $+35.2 \pm 46.3$ & 0.27 & $+24.9 \pm 24.3$ & 0.77 & $+23 \pm 27.1$ \\
\hline$\triangle \mathrm{PaO}_{2} / \mathrm{FIO}_{2}(\mathrm{mmHg})$ & $+46.1 \pm 51.2$ & 0.25 & $+33.3 \pm 35.8$ & 0.27 & $+47.3 \pm 60.6$ \\
\hline$\triangle \mathrm{SaO}_{2}(\%)$ & $+5 \pm 4.6$ & 0.84 & $+5.2 \pm 5.6$ & 0.10 & $+3.3 \pm 3.3$ \\
\hline \multicolumn{6}{|l|}{$\mathrm{CO}_{2}$ clearance } \\
\hline$\triangle \mathrm{PaCO}_{2}(\mathrm{mmHg})$ & $-0.78 \pm 3.3$ & 0.027 & $+1.29 \pm 3.94$ & 0.33 & $+0.33 \pm 3.8$ \\
\hline$\triangle \mathrm{EtCO}_{2}(\mathrm{mmHg})$ & $+1.5 \pm 2.6$ & 0.62 & $+1.9 \pm 2.4$ & 0.60 & $+1.44 \pm 3.5$ \\
\hline$\triangle$ Alveolar dead space & $-0.05 \pm 0.08$ & 0.10 & $-0.016 \pm 0.066$ & 0.91 & $-0.019 \pm 0.086$ \\
\hline$\Delta$ ventilatory ratio & $-0.02 \pm 0.1$ & 0.02 & $+0.07 \pm 0.21$ & 0.09 & $0 \pm 0.14$ \\
\hline \multicolumn{6}{|l|}{ Respiratory mechanics } \\
\hline$\Delta$ plateau pressure $\left(\mathrm{cmH}_{2} \mathrm{O}\right)$ & $7.9 \pm 3.2$ & 0.002 & $+10.6 \pm 2.9$ & 0.29 & $+9.9 \pm 2.6$ \\
\hline$\Delta$ driving pressure $\left(\mathrm{cmH}_{2} \mathrm{O}\right)$ & $-1 \pm 3.3$ & 0.016 & $+1 \pm 2.6$ & 0.25 & $+0.23 \pm 2.7$ \\
\hline$\Delta \mathrm{Crs}\left(\mathrm{ml} / \mathrm{cmH}_{2} \mathrm{O}\right)$ & $+2.5 \pm 8.4$ & 0.02 & $-4.1 \pm 12.5$ & 0.21 & $+0.28 \pm 15.3$ \\
\hline \multicolumn{6}{|l|}{ Hemodynamics } \\
\hline$\Delta$ Heart rate $(b p m)$ & $-10 \pm 25$ & 0.07 & $-1 \pm 7$ & 0.45 & $-2 \pm 6$ \\
\hline$\triangle$ Mean arterial pressure (bpm) & $-3.7 \pm 8.1$ & 0.12 & $-0.1 \pm 9.8$ & 0.89 & $+0.3 \pm 9.3$ \\
\hline$\triangle \mathrm{SvO}_{2}(\%)$ & $+2.9 \pm 4.9$ & 0.32 & $+4.4 \pm 6.2$ & 0.051 & $-0.2 \pm 8.7$ \\
\hline$\Delta(\mathrm{a}-\mathrm{v}) \mathrm{O}_{2}$ difference $(\mathrm{ml} / \mathrm{dl})$ & $+0.38 \pm 0.42$ & 0.51 & $+0.49 \pm 0.82$ & 0.93 & $+0.52 \pm 0.88$ \\
\hline$\Delta$ venous admixture & $-0.12 \pm 0.11$ & 0.54 & $-0.13 \pm 0.11$ & 0.88 & $-0.14 \pm 0.18$ \\
\hline
\end{tabular}

Changes of gas exchange, respiratory mechanics and hemodynamics increasing positive-end expiratory pressure from 5 to $15 \mathrm{cmH}_{2} \mathrm{O}$ measured in COVID-19-ARDS (CARDS, middle column) and the two historical matched cohorts $\left(\mathrm{PaO}_{2} / \mathrm{FiO}_{2}\right.$-matched-ARDS, left column and Compliance-matched-ARDS, right column). The change of a variable $(\Delta)$ is calculated as the value at $15 \mathrm{cmH}_{2} \mathrm{O}-$ value at $5 \mathrm{cmH}_{2} \mathrm{O}$

$\mathrm{PaO}_{2}$ arterial partial pressure of oxygen, $\mathrm{PAO}_{2}$ alveolar partial pressure of oxygen, $\mathrm{A}-\mathrm{aO}_{2}$ alveolar-arterial oxygen partial pressure difference, $\mathrm{SaO}$, hemoglobin saturation of the arterial blood, $\mathrm{PaCO}_{2}$ arterial partial pressure of carbon dioxide, $\mathrm{PETCO}_{2}$ end-tidal partial pressure of carbon dioxide, $\mathrm{ScVO} \mathrm{O}_{2}$ hemoglobin saturation of the central venous blood, $(a-v) \mathrm{O}_{2}$ difference arterial-venous difference of oxygen content

\section{Respiratory system compliance and lung gas volume}

The relative importance of $V_{\mathrm{A}} / Q$ mismatching as opposed to right-to-left shunt in COVID-19-ARDS is consistent with its relatively higher lung gas volume, which correlates with the respiratory system compliance (see Figure E4). Moreover, the gas volume was remarkably higher in COVID-19-ARDS compared to $\mathrm{PaO}_{2} / \mathrm{FiO}_{2}$-matchedARDS for each lung section along the gravitational axis, including the most dependent ones, which are almost gasless in typical ARDS (Fig. 2). Again, this difference, likely due to the vasocentric nature of COVID-19-ARDS (as compared to 'gas space-centered' nature of typical ARDS), is not entirely surprising. Unexpectedly, however, we found that Compliance-matched-ARDS patients had lower gas volume than did COVID-19-ARDS patients, despite having similar values of respiratory system mechanics. The interpretation of these findings is currently only speculative. However, it is tempting to hypothesize that the increased gas volume in COVID19-ARDS is caused by newly formed emphysema-like functional regions that may develop as a consequence of the ischemic changes and diffuse micro thromboses described in autopsy findings $[11,14]$.

\section{Response to PEEP}

The improved oxygenation in our $\mathrm{PaO}_{2} / \mathrm{FiO}_{2}$-matchedARDS patient cohort in response to the PEEP test was likely due recruitment. Indeed, these patients were more recruitable, as indicated by higher baseline non-aerated tissue mass in conjunction with a significant decrease of plateau pressure and an improvement of Crs when PEEP was raised. In contrast, Compliance-matched-ARDS and COVID-19ARDS patients, with lower baseline non-aerated tissue mass, showed unaltered or worsened respiratory system mechanics and $\mathrm{PaCO}_{2}$ in response to the PEEP test (Table 3). These findings suggest-in line with previous observations-[32, 33 ] that the primary mechanism of oxygenation improvement was a decrease/redistribution of blood flow away from airless zones rather than recruitment.

\section{Atypical features of COVID-19-ARDS}

Our data suggest that COVID-19-ARDS is an atypical subset of ARDS. We may then wonder why, for a given severity of hypoxemia, the Crs values of our COVID19-ARDS patients appear higher than those reported by other authors [6,34]. As the virus is the same worldwide, its manifestations everywhere should be more or less consistent. The differences observed among various 
reports may depend on two main factors: the timing of the observations and the conditions of measurement. Indeed, COVID-19-ARDS evolves rather rapidly with time, as reflected by a CT scan appearance that shifts progressively from bilateral ground glass opacities to overt consolidations/collapse [35]. Crs changes accordingly [36]. It is not surprising that, with passing time, Crs may decrease to impressively low values. The conditions of measurement are also important. Most studies, such as the largest one yet published on COVID-19 pathophysiology [8], report Crs values measured under the prevailing "clinical conditions". In all cohorts of our COVID-19-ARDS, $\quad \mathrm{PaO}_{2} / \mathrm{FiO}_{2}$-matched-ARDS and Compliance-matched-ARDS populations, all measurements were performed at a standard PEEP of $5 \mathrm{cmH}_{2} \mathrm{O}$. It is obvious that Crs measured at $10-15 \mathrm{cmH}_{2} \mathrm{O}$ of PEEP may lead to different values than those we report here.

\section{Clinical implications}

Our COVID-19-ARDS patients were studied $9.6 \pm 4$ days after the onset of symptoms and were compared with "early" historical ARDS patients (within 1 week from admission). Within this initial timeframe, the sharp physio-anatomic distinctions between non-COVID-ARDS and COVID-19ARDS suggest the need to modify our standard practice of ARDS management for COVID-19 patients. Specifically, the dramatically greater gas volume and better compliance of COVID-19 lungs, when present, discourage interventions intended to further inflate the lungs. Indeed, for a similar marginal improvement of oxygenation in response to a PEEP increment, signs of overdistension became manifest in our COVID-19 patients. In contrast, respiratory mechanics improved and $\mathrm{PaCO}_{2}$ decreased in the $\mathrm{PaO}_{2} / \mathrm{FiO}_{2}$-matchedARDS cohort. Attempts to aggressively recruit the lung to improve $\mathrm{O}_{2}$ exchange by applying higher than customary levels of mean airway pressure seem ill-advised during this early disease phase. We must stress, however, that COVID19 pneumonia rapidly evolves with time. Consequently, the safest ventilatory strategy could well be different at different stages which range from initial modest ground-glass opacities with preserved $\mathrm{Crs}$ to an intermediate stage (as described in the present study), to a final stage characterized by extensive opacities, prevalent fibrosis, and very low Crs.

\section{Limitations}

These data are unique in documenting physiologic measurements and quantitative images under identical conditions in closely matched COVID-19-ARDS and non-COVID-ARDS patients. However, our study has several limitations: first, the limited size of our historical ARDS dataset. Second, patients were enrolled in a single center, within a limited time frame of their illnesses. Earlier or later stages may present sharply different behaviors. In addition, we did not perform a second CT scan at $15 \mathrm{cmH}_{2} \mathrm{O}$. Finally, a comprehensive set of hemodynamic data were not acquired, preventing full characterization of the mechanisms underlying the gas exchange variations we observed.

\section{Conclusion}

COVID-19-ARDS and non-COVID ARDS patients differ significantly in their radiological and physiological features, both in terms of the relationship between oxygenation and lung mechanics and their responses to PEEP. The different stages of the disease call for a rethinking of the traditional lung protective ventilation targets which take into account the peculiarities of this novel ARDS variant.

\section{Electronic supplementary material}

The online version of this article (https://doi.org/10.1007/s00134-020-06281-2) contains supplementary material, which is available to authorized users.

\begin{abstract}
Author details
${ }^{1}$ Department of Anesthesiology and Intensive Care, ASST Santi e Paolo Hospital, University of Milan, Milan, Italy. ${ }^{2}$ Department of Anesthesiology, Intensive Care and Emergency Medicine, Medical University of Göttingen, Robert-Koch Straße 40, Göttingen, Germany. ${ }^{3}$ Department of Radiology, San Gerardo Hospital, Monza, Italy. ${ }^{4}$ Department of Adult Critical Care, Guy's and St Thomas' NHS Foundation Trust, Health Centre for Human and Applied Physiological Sciences, London, UK. ${ }^{5}$ Department of Pulmonary and Critical Care Medicine, University of Minnesota and Regions Hospital, St. Paul, Minnesota, USA.
\end{abstract}

\section{Acknowledgements}

We would like to thank Sartorius AG, Göttingen, Germany for an unrestricted grant for lung injury-related research towards the Department of Anesthesiology of Göttingen University Medical Center.

\section{Author contributions}

Conception and design: DC, SC, PF, MC. Data collection: SC, FR, PF, MB, TP, MMP, MC, PH. Analysis and interpretation: MB, KM, LC, MQ, LG. Drafting the manuscript for important intellectual content: DC, LC, JJM, LG.

Funding

Open Access funding enabled and organized by Projekt DEAL. Institutional.

Compliance with ethical standards

\section{Conflicts of interest}

The authors have no interests to disclose.

\section{Ethics approval}

Ethics Committee approval that allows physiological and CT study for all patients with severe respiratory failure admitted to our critical care unit (ethical committee numbers: 42937/2016 and 9890/2017).

\section{Consent to participate}

None.

Consent for publication

All authors have approved the manuscript. 


\section{Availability of data and material}

Dataset available upon reasonable request.

\section{Open Access}

This article is licensed under a Creative Commons Attribution-NonCommercial 4.0 International License, which permits any non-commercial use, sharing, adaptation, distribution and reproduction in any medium or format, as long as you give appropriate credit to the original author(s) and the source, provide a link to the Creative Commons licence, and indicate if changes were made. The images or other third party material in this article are included in the article's Creative Commons licence, unless indicated otherwise in a credit line to the material. If material is not included in the article's Creative Commons licence and your intended use is not permitted by statutory regulation or exceeds the permitted use, you will need to obtain permission directly from the copyright holder. To view a copy of this licence, visit http://creativecommons.org/licen ses/by-nc/4.0/.

\section{Publisher's Note}

Springer Nature remains neutral with regard to jurisdictional claims in published maps and institutional affiliations.

\section{Received: 7 September 2020 Accepted: 5 October 2020} Published online: 21 October 2020

\section{References}

1. Ranieri VM, Rubenfeld GD, Thompson BT, Ferguson ND et al (2012) Acute respiratory distress syndrome: the Berlin Definition. JAMA 307(23):2526-2533

2. Gattinoni L, Coppola S, Cressoni M, Busana M et al (2020) COVID-19 does not lead to a "Typical" acute respiratory distress syndrome. Am J Respir Crit Care Med 201(10):1299-1300

3. Gattinoni L, Chiumello D, Caironi P, Busana M et al (2020) COVID-19 pneumonia: different respiratory treatments for different phenotypes? Intensive Care Med 46(6):1099-1102

4. Schenck EJ, Hoffman K, Goyal P, Choi J et al (2020) Respiratory mechanics and gas exchange in COVID-19-associated respiratory failure. Ann Am Thorac Soc 17(9):1158-1161

5. Ferrando C, Suarez-Sipmann F, Mellado-Artigas R, Hernandez M et al (2020) Clinical features, ventilatory management, and outcome of ARDS caused by COVID-19 are similar to other causes of ARDS. Intensive Care Med. https://doi.org/10.1007/s00134-020-06192-2

6. Ziehr DR, Alladina J, Petri CR, Maley JH, Moskowitz A, Medoff BD, Hibbert KA, Thompson BT, Hardin CC (2020) Respiratory pathophysiology of mechanically ventilated patients with COVID-19: a cohort study. Am J Respir Crit Care Med 201(12):1560-1564

7. Cummings MJ, Baldwin MR, Abrams D, Jacobson SD et al (2020) Epidemiology, clinical course, and outcomes of critically ill adults with COVID-19 in New York City: a prospective cohort study. Lancet 395(10239):1763-1770

8. Grasselli G, Tonetti T, Protti A, Langer T et al (2020) Pathophysiology of COVID-19-associated acute respiratory distress syndrome: a multicentre prospective observational study. Lancet Respir Med. https://doi. org/10.1016/S2213-2600(20)30370-2

9. Fan E, Beitler JR, Brochard L, Calfee CS et al (2020) COVID-19-associated acute respiratory distress syndrome: is a different approach to management warranted? Lancet Respir Med 8(8):816-821

10. Ferguson ND, Fan E, Camporota L, Antonelli M et al (2012) The Berlin definition of ARDS: an expanded rationale, justification, and supplementary material. Intensive Care Med 38(10):1573-1582

11. Ackermann M, Verleden SE, Kuehnel M, Haverich A et al (2020) Pulmonary Vascular Endothelialitis, Thrombosis, and Angiogenesis in Covid-19. N Engl J Med 383(2):120-128

12. Santamarina MG, Boisier D, Contreras R, Baque M et al (2020) COVID-19: a hypothesis regarding the ventilation-perfusion mismatch. Crit Care 24(1):395

13. Teuwen LA, Geldhof V, Pasut A, Carmeliet P (2020) COVID-19: the vasculature unleashed. Nat Rev Immunol 20(7):389-391

14. Wichmann D, Sperhake JP, Lutgehetmann M, Steurer S et al (2020) Autopsy findings and venous thromboembolism in patients with covid19: a prospective cohort study. Ann Intern Med 173(4):268-277
15. Patel BV, Arachchillage DJ, Ridge CA, Bianchi P et al (2020) Pulmonary Angiopathy in Severe COVID-19: physiologic, imaging, and hematologic observations. Am J Respir Crit Care Med 202(5):690-699

16. Tomashefski JF Jr, Davies P, Boggis C, Greene R et al (1983) The pulmonary vascular lesions of the adult respiratory distress syndrome. Am J Pathol 112(1):112-126

17. Vesconi S, Rossi GP, Pesenti A, Fumagalli R et al (1988) Pulmonary microthrombosis in severe adult respiratory distress syndrome. Crit Care Med 16(2):111-113

18. Greene R, Zapol WM, Snider MT, Reid L et al (1981) Early bedside detection of pulmonary vascular occlusion during acute respiratory failure. Am Rev Respir Dis 124(5):593-601

19. Shi H, Han X, Jiang N, Cao Y et al (2020) Radiological findings from 81 patients with COVID-19 pneumonia in Wuhan, China: a descriptive study. Lancet Infect Dis 20(4):425-434

20. Zhang L, Feng X, Zhang D, Jiang C et al (2020) Deep vein thrombosis in hospitalized patients with COVID-19 in Wuhan, China: prevalence, risk factors, and outcome. Circulation 142(2):114-128

21. Lang M, Som A, Mendoza DP, Flores EJ, Reid N, Carey D, Li MD, Witkin A, Rodriguez-Lopez JM, Shepard JO, Little BP (2020) Hypoxaemia related to COVID-19: vascular and perfusion abnormalities on dual-energy CT. Lancet Infect Dis. https://doi.org/10.1016/S1473-3099(20)30367-4

22. Ladakis C, Myrianthefs P, Karabinis A, Karatzas G et al (2001) Central venous and mixed venous oxygen saturation in critically ill patients. Respiration 68(3):279-285

23. Herrmann P, Nguyen XP, Luecke T, Quintel M (2002) MALUNA 1.03 ein Softwaretool zur analyse computertomographischer Schnittbilder del Lunge. In: Jamal R, Jaschinski H (eds) Virtuelle instrumente in der praxis. Huethig Verlag, Heidelberg, pp 389-395

24. Stuart EA (2010) Matching methods for causal inference: A review and a look forward. Stat Sci 25(1):1-21

25. Bellani G, Laffey JG, Pham T, Fan E et al (2016) Epidemiology, patterns of care, and mortality for patients with acute respiratory distress syndrome in intensive care units in 50 countries. JAMA 315(8):788-800

26. Caironi P, Carlesso E, Cressoni M, Chiumello D et al (2015) Lung recruitability is better estimated according to the Berlin definition of acute respiratory distress syndrome at standard $5 \mathrm{~cm} \mathrm{H}_{2} \mathrm{O}$ rather than higher positive end-expiratory pressure: a retrospective cohort study. Crit Care Med 43(4):781-790

27. Riley RL, Cournand A (1949) Ideal alveolar air and the analysis of ventilation-perfusion relationships in the lungs. J Appl Physiol 1(12):825-847

28. Reske AW, Costa EL, Reske AP, Rau A et al (2013) Bedside estimation of nonaerated lung tissue using blood gas analysis. Crit Care Med 41(3):732-743

29. Gattinoni L, Caironi P, Cressoni M, Chiumello D et al (2006) Lung recruitment in patients with the acute respiratory distress syndrome. N Engl J Med 354(17):1775-1786

30. Henderson WR, Chen L, Amato MBP, Brochard LJ (2017) Fifty Years of Research in ARDS. Respiratory Mechanics in Acute Respiratory Distress Syndrome. Am J Respir Crit Care Med 196(7):822-833

31. Diehl JL, Mercat A, Pesenti A (2019) Understanding hypoxemia on ECCO2R: back to the alveolar gas equation. Intensive Care Med 45(2):255-256

32. Pan C, Chen L, Lu C, Zhang W et al (2020) Lung recruitability in COVID19-associated acute respiratory distress syndrome: a single-center observational study. Am J Respir Crit Care Med 201(10):1294-1297

33. Roesthuis $L$, van den Berg M, van der Hoeven H (2020) Advanced respiratory monitoring in COVID-19 patients: use less PEEP! Crit Care 24(1):230

34. Bos LDJ, Paulus F, Vlaar APJ, Beenen LFM et al (2020) Subphenotyping acute respiratory distress syndrome in patients with COVID-19: consequences for ventilator management. Ann Am Thorac Soc 17(9):1161-1163

35. Shi H, Han X, Jiang N, Cao Y, Alwalid O, Gu J, Fan Y, Zheng C (2020) Radiological findings from 81 patients with COVID-19 pneumonia in Wuhan, China: a descriptive study. Lancet Infect Dis 20:425-434

36. Gattinoni L, Coppola S, Cressoni M, Busana M et al (2020) Reply by Gattinoni et al. to Hedenstierna et al., to Maley et al., to Fowler et al., to Bhatia and Mohammed, to Bos, to Koumbourlis and Motoyama, and to Haouzi et al. Am J Respir Crit Care Med 202(4):628-630 